\title{
Hypothetic immunopathological impacts of SARS-CoV-2 and HIV co-infection on COVID-19 severity
}

\author{
Idris Nasir Abdullahi, ${ }^{1}$ Abdurrahman Elfulaty Ahmad, ${ }^{1}$ Anthony Uchenna Emeribe ${ }^{2}$ \\ ${ }^{1}$ Department of Medical Laboratory Science, Faculty of Allied Health Sciences, College of Medical Sciences, Ahmadu Bello \\ University, Zaria; ${ }^{2}$ Department of Medical Laboratory Science, University of Calabar, Calabar, Nigeria
}

To the Editor,

The world is currently battling against and trying to survive yet another pandemic that threatens human health security. Severe acute respiratory syndromecoronavirus-2 (SARS-CoV-2), the etiological agent of coronavirus disease 19 (COVID-19), is one of the three most virulent coronaviruses (CoVs). Based on available clinical details, the geriatric group of over 65 years of age and persons with chronic comorbidities such as type-2 diabetes mellitus, chronic obstructive pulmonary disease, cardiovascular diseases, and immunodeficiencies tend to rapidly develop multiorgan failure, severe COVID-19 and ultimately, death. ${ }^{1}$ As at 1:10 PM GMT $+1,5^{\text {th }}$ May 2020, the global case fatality rate of COVID-19 was approximately $6.9 \%$, whereas $49,623(2 \%)$ of SARS-CoV-2 infected persons were in critical clinical conditions, including acute respiratory distress with or without metabolic acidosis, coagulopathy, and hypoxia. ${ }^{2}$

Correspondence: Idris Nasir Abdullahi, Department of Medical Laboratory Science, Faculty of Allied Health Sciences, Ahmadu Bello University, PMB 05 along Samaru, Zaria, Nigeria.

Tel.: +2348027771068 - Fax: +2348030522324 .

E-mail: inabdullahi@abu.edu.ng; eedris888@yahoo.com

Key words: COVID-19; SARS-CoV-2; HIV co-infection; immunopathology.

Contributions: INA conceptualized and designed study; INA, AEA and AUE contributed equally to literature search, drafting the first manuscript, and reviewing for intellectual content. All authors approved the final manuscript before submission.

Received for publication: 15 April 2020.

Revision received: 5 May 2020.

Accepted for publication: 15 May 2020.

This work is licensed under a Creative Commons Attribution NonCommercial 4.0 License (CC BY-NC 4.0).

${ }^{\circ}$ Copyright: the Author(s), 2020

Licensee PAGEPress, Italy

Italian Journal of Medicine 2020; 14:189-191

doi:10.4081/itjm.2020.1291
To date, very few studies have demonstrated the clinical course of COVID-19 in people living with HIV/AIDS. HIV/AIDS patients are believed to be susceptible to COVID-19, including other opportunistic pathogens due to their compromised immune function. It is assumed that persons who are immunocompromised could have an aggravated pathogenesis of COVID-19 via the activation of chronic inflammatory response. ${ }^{3}$ Before the advent of effective highly active antiretroviral therapy (ART), HIV-infected persons with $\mathrm{CD} 4^{+} \mathrm{T}$ cell count less than 200 cells $/ \mathrm{mm}^{3}$ were considered to be at high risk of complications associated with respiratory tract infections. ${ }^{4}$ Whether this could hold for COVID-19 is yet to be elucidated. It is worthy to note that some persons living with HIV/AIDS and other comorbidities, especially cardiovascular and pulmonary disorders have an increased risk for a more severe course of COVID-19. ${ }^{5}$ Thus, additional care for all people living with HIV, especially those with low $\mathrm{CD} 4^{+} \mathrm{T}$ cell counts or poorly controlled HIV is necessary. Considering the burden of the global HIV epidemic with a disproportionate concentration in sub-Saharan Africa, Asia and certain parts of Southern Europe, additional preventive measures and management strategies are crucial. ${ }^{6}$

One of the few studies that investigated the clinical interactions of HIV with COVID-19 was that of Guo et al. ${ }^{7}$ In their study of 1174 HIV infected patients in Wuhan, China $0.68 \%$ was confirmed SARS-CoV-2 positive. Importantly, all the HIV-SARS-CoV-2 co-infected patients had HIV load (VL) of $<20$ copies $/ \mu \mathrm{L}$ had relatively adequate $\mathrm{CD} 4^{+} \mathrm{T}$ cell counts and clinical symptoms for COVID-19. ${ }^{7}$ These indicate that good cellular immunity and low HIV VL could probably facilitate symptomatic COVID-19. Conversely, the study further indicated that HIV/AIDS patients with very low $\mathrm{CD}^{+} \mathrm{T}$ cell counts were asymptomatic. It could be because several asymptomatic individuals may have missed laboratory testing, even though they were SARS-CoV-2 infected. This supports the hypothesis that immune-compromised HIV/AIDS patients might have some protection from a clinical and severe SARS-CoV attack due to profound anti-inflammatory 
response which neutralizes the cytokine storm associated with symptomatic COVID-19. ${ }^{7}$ Similar findings that were corroborated by the assertions above are those seen in $\mathrm{CD} 4^{+}$lymphopenic HIV patient who recovered from SARS-CoV-2 infection. ${ }^{8}$

In another report, 5 out of 543 COVID-19 patients were HIV co-infected in Spain. ${ }^{9}$ Four out of the 5 patients had a low HIV viral load $(<50$ copies $/ \mathrm{mL})$. Of these, 2 were on protease-inhibitor-based ART, while the other two were on dolutegravir-based ART. ${ }^{9}$ The $\mathrm{CD}^{+} \mathrm{T}$ cell counts of all those on ART were $>400$ cells $/ \mathrm{mm}^{3}$. However, the $5^{\text {th }}$ ART-naive patient had a very advanced HIV/AIDS stage with $\mathrm{CD}^{+} \mathrm{T}$ cell count of 13 cells $/ \mathrm{mm}^{3} .{ }^{9}$ Of note, one of the ART experienced, and the ART-naive patients were in severe COVID-19 conditions. As a marker of inflammation, the serum ferritin level of the ART-naive patient was significantly low compared with those on ART. Upon diagnosis, all the 5 patients were immediately placed on anti-SARSCoV-2 and were switched to boosted-protease inhibitor ART because HIV protease inhibitors may have antagonistic activity against SARS-CoV-2 protease inhibitors. ${ }^{9}$ Eventually, the ART-naive alongside 3 of the ART experienced patients were cured of COVID-19. Whereas, one of the initial ART experienced patients with low HIV VL had no sustained SARS-CoV-2 response and remained in intensive care. ${ }^{9}$

Immuno-pathologically, an HIV-associated immunodeficiency leads to cytokine and chemokine dysregulation. ${ }^{10}$ Undoubtedly, the host immunologic response is vital for the control and resolution of $\mathrm{CoV}$ infections. However, it can also lead to immunopathology, when the immune response is out of control, especially if Th1 and Th17 subsets are activated due to exacerbated immune response. ${ }^{11}$ For instance, some plasma cytokines such as tumor necrosis factor- $\alpha$, interleukins (IL-) 2, 6, and 10 were elevated in COVID19 patients. ${ }^{11}$ Their upregulation culminates in the induction of virus-induced inflammatory storm, one of the major critical conditions experienced by COVID-19 patients. $^{5}$ Thus, when individuals living HIV/AIDS eventually get infected with SARS-CoV2 , it is expected they experience synergistic cytokine storm and chronic inflammatory response. In addition, $\mathrm{T}$ cell activation and regulation have been shown to increase significantly in COVID-19 patients. ${ }^{12}$ In particular, a significant decrease in absolute lymphocyte counts in severe cases of COVID-19 has been reported. ${ }^{12} \mathrm{CD} 4^{+}$and $\mathrm{CD} 8^{+} \mathrm{T}$ cells lymphocytopenia were seen primarily in severe cases due to lymphocyte exhaustion. ${ }^{12}$ These immunological features could be dangerous for people living with HIV/AIDS, especially the ART-naive ones.

Considering the sustained global rise in the incidence and spread of SARS-CoV-2, there is an urgent need for antiviral drugs that can contain the replication of both HIV and SARS-CoV-2. For instance, Dolutegravir and Lopinavir/Ritonavir have been recommended by scientists to potentially help to prevent or treat severe COVID-19. ${ }^{13,14}$ In addition, remdesivir has been used in many clinical trials to treat COVID-19. Notably, the protease inhibitor, lopinavir/ritonavir, was recommended for the management of COVID-19 based on the experience gained during SARS and MERS epidemics. Recently, the Food and Drug Administration (FDA) of the United States of America issued an emergency approval for the use of remdesivir in the treatment of severe COVID-19. ${ }^{15}$

There is a need for clinicians to carefully evaluate COVID-19 patients for HIV co-infection, especially in high-risk persons such as men who have sex with men (MSM), commercial sex workers, and injection drug users. If found co-infected, these patients should be thoroughly evaluated to determine the most suitable antiviral regimen that could contain both pathogens. In addition, more health education programs that explain the impacts of high-risk activities on HIV and SARS-CoV-2 infections should be implemented.

More studies are needed on the clinical presentations of COVID-19 patients with HIV co-infection, especially from HIV endemic regions, in order to have a better understanding of the immunological and pathological impacts of either pathogen on the other. Finally, it is highly recommended to perform comprehensive evaluation studies on all candidate antiviral agents used in treating HIV/SARS-CoV-2 co-infection in order to assure their potency, efficacy, and safety.

\section{References}

1. Huang C, Wang Y, Li X, et al. Clinical features of patients infected with 2019 novel coronavirus in Wuhan, China. Lancet 2020;395:497-506.

2. Coronavirus Update (Live): 3669604 cases and 253166 deaths from COVID-19 Virus Outbreak-Worldometer. Available from: https://www.worldometers.info/coronavirus/ Accessed: $5^{\text {th }}$ May, 2020.

3. Shaker MS, Oppenheimer J, Grayson M, et al. COVID19: Pandemic Contingency Planning for the Allergy and Immunology Clinic. The American Academy of Allergy, Asthma \& Immunology; 2020. Available from: https:/education.aaaai.org/sites/default/files/COVID19_ US\%20FINAL.pdf Accessed: 24 ${ }^{\text {th }}$ March, 2020.

4. National Institutes for Health; US Department of Health and Human Services. Interim Guideline for COVID-19 and persons with HIV; 2020. Available from: https://aidsinfo.nih.gov/guidelines/html/8/covid-19-andpersons-with-hiv-interim-guidance-/554/interim-guidance-for-covid-19-and-persons-with-hiv 2020 Accessed: $24^{\text {th }}$ March, 2020.

5. Guo Y, Cao Q, Hong Z, et al. The origin, transmission and clinical therapies on coronavirus disease 2019 (COVID-19) outbreak - an update on the status. Research 2020;7:11. 
6. Dwyer-lindgren L, Cork MA, Sligar A, et al. Mapping HIV prevalence in sub-Saharan Africa between 2000 and 2017. Nature 2019;570:189.

7. Guo W, Ming F, Dong Y, et al. A Survey for COVID-19 among HIV/AIDS patients in two districts of Wuhan, China. Lancet 2020; available from: https://ssrn.com/abstract $=3550029$

8. Zhu F, Cao Y, Xu S, Zhou M. Coinfection of SARSCoV-2 and HIV in a patient in Wuhan city, China. J Med Virol 2020 [Epub ahead of print].

9. Blanco JL, Ambrosioni J, Garcia F, et al on behalf the COVID-19 in HIV Investigators. COVID-19 in patients with HIV: clinical case series. Lancet 2020. [Epub ahead of print].

10. Akase IE, Musa BOP, Obiako RO, et al. Immune Dysfunction in HIV: a possible role for pro- and anti-inflammatory cytokines in HIV staging. J Immunol Res 2017;4128398.

11. Chen C, Zhang XR, Ju ZY, He WF. Advances in the research of cytokine storm mechanism induced by Corona
Virus Disease 2019 and the corresponding immunotherapies. Zhonghua Shaoshang Zazhi 2020;36:E005.

12. Zheng $H$, Zhang M, Yang $C$, et al. Elevated exhaustion levels and reduced functional diversity of $\mathrm{T}$ cells in peripheral blood may predict severe progression in COVID-19 patients. Cell Mol Immunol 2020. [Epub ahead of print].

13. Beck BR, Shin B, Choi Y, et al. Predicting commercially available antiviral drugs that may act on the novel coronavirus (2019-nCoV), Wuhan, China through a drug-target interaction deep learning model. Comput Struct Biotechnol J 2020;18:784-90.

14. Gao K, Nguyen DD, Wang R, Wei G-W. Machine intelligence design of 2019-nCoV drugs. bioRxiv 2020. [Epub ahead of print].

15. FDA issues emergency-use authorization for remdesivir to treat hospitalized patients with severe Covid-19. Available from: https://www.fda.gov/media/137564/ download Last accessed: $5^{\text {th }}$ May, 2020. 